\title{
A Crítica de Nietzsche à Verdade: Em "Busca" de Conhecimento Enquanto Criação
}

\author{
Marco Sabatini
}

\section{Resumo:}

Partindo da crítica de Nietzsche à filosofia de Platão, este trabalho objetiva demonstrar que na filosofia nietzschiana existe uma perspectiva sobre o conhecimento que se confronta com o método de conhecimento platônico e que esta perspectiva de Nietzsche permite falarmos do conhecimento enquanto criação humana não dogmática. Primeiro, a análise se concentra nos argumentos sobre a verdade e a metafísica da filosofia platônica para focar a crítica nietzschiana de que a busca pela verdade a fim do conhecimento na filosofia de Platão leva a um aprisionamento físico-teórico humano. Como consequência, revela-se outro tipo de conhecimento adequado apenas aos espíritos livres, como diz Nietzsche. Mostrando-se dessemelhante à filosófica platônica, este conhecimento surge enquanto criação da vida - de seus próprios valores.

Palavras-chave: Verdade, metafísica e conhecimento. 


\section{Introdução}

O conhecimento para Nietzsche, assim como diversos outros pontos de sua filosofia, se ramifica em uma complexa trama de concepções que lhe dão significados díspares conforme o contexto em que ele é estudado. Nota-se que há uma espécie de escala de tipos de conhecimento onde cada um revela o seu grau de valor perante os outros e, com isso, uma posição hierárquica. Associado ao tipo de conhecimento, conseqüente e intrinsecamente, está o próprio conhecer; ou seja, mesmo fazendo parte de uma única situação, o ato-forma de conhecer é diferente do que seria uma "espécie de produto" , isto é, do conhecimento. Assim, quando se considera alguns fragmentos de Nietzsche, percebe-se diversas circunstâncias em que o filósofo situa, nessa hierarquia, graus de conhecimentos mais elevados do que outros, a partir de uma análise moral e fisiológica do próprio ato de conhecer. Dessa forma, a ação que leva ao conhecimento faz parte da própria vida, ou melhor, de formas de vida que também se posicionam conforme as suas grandezas. Por isso, para fazer um estudo completo sobre o conhecimento em Nietzsche, seria necessário identificar cada um desses tipos adjuntos às condições morais e fisiológicas que eles expõem.

Porém, este artigo se sustenta em um ponto mais detalhado. Sabendo que na filosofia de Nietzsche não existe apenas uma interpretação sobre o conhecimento e que são elas que criam uma hierarquia cujos pontos mais elevados possuem um maior valor, pode-se dividir essa escala em dois grupos: um em que o conhecimento faz parte de homens/forças fortes e o outro grupo em que ele faz parte de homens/forças fracas; isto é, são forças que se dividem basicamente em ativas - as dos fortes - e reativas - as dos fracos. É justamente o tipo de conhecimento pertencente ao grupo forte que me interessa, pois ele parece confrontar com um outro tipo de conhecimento que busca a verdade metafísica, ou seja, o método socrático-platônico ${ }^{2}$. A problemática surge, então, quando este tipo de conhecimento se confronta com o método socrático de busca pela verdade

I "Espécie de produto": as aspas são necessárias, aqui, para que a tentativa de simplificar a idéia entre conhecer-conhecimento não se torne uma interpretação errônea do pensamento de Nietzsche. Ambos não estão separados, apesar de serem diferentes: determinado ato de conhecer gera determinado tipo de conhecimento de modo que a separação entre eles não faria sentido algum, já que participam de um mesmo "processo".

2 Há alguns aforismos em que Nietzsche crítica Platão e Sócrates como se ambos fossem um só, e outros em que Nietzsche defende Platão contra Sócrates. O ponto interessante parece surgir quando Nietzsche fala da filosofia de Platão e quando ele fala de sua vida: enquanto filósofo, Platão seria apenas mais um décadent influenciado por Sócrates e sua moral de modo tão intenso que ambos se "transformaram" em uma única pessoa; mas, quando Nietzsche fala de Platão enquanto pessoa, corpo, homem, ele parece mudar o tom: 
metafísica, em que se desdobra a hipótese de que este tipo de conhecimento só existe enquanto criação ${ }^{3} \mathrm{e}$, por isso, diferente da verdade metafísica platônica.

\section{Caracterização do Problema}

"O sancta simplicitas! Em que curiosa simplificação e falsificação vive o homem!"(NIETZSCHE, 2005, p. 29). No capítulo segundo ("O Espírito Livre") de Além do bem e do mal, Nietzsche começa o seu raciocínio de uma forma muito interessante: logo de início, ele afirma que o homem vive em uma simplificação e em uma falsificação. Não há nenhum complemento, nenhuma palavra que defina esta simplificação e esta falsificação, ou seja, ele não fala que, em uma determinada situação, a aparência dá uma sensação falsa de verdade para o homem; ao contrário: Nietzsche fala em um contexto tão geral que nos leva a pensar que tudo que o homem vive é esta curiosa simplificação e falsificação (e não seria justamente isso que ele queria?). No entanto, as conseqüências seriam amplas: ora, todas as interpretações humanas, todas as verdades, imaginações, em suma, todo tipo de pensamento e ato humanos, mesmo enquanto perspectivas, seriam apenas falsificação, seriam apenas o engano ou ao menos a incerteza de quem considera algo como certo, verdadeiro, incontestável. E, por isso mesmo, tudo seria a simplificação em que vivemos? E o conhecimento? E todos os estudos? Tudo falsificação? Tanta complexidade em um cenário simples e mentiroso?

E Nietzsche continua:

Como soubermos dar a nossos sentidos um passo livre para tudo que é superficial, e a nosso pensamento um divino desejo de saltos caprichosos e pseudoconclusões - como conseguimos desde o princípio manter nossa ignorância, para gozar de uma quase inconcebível liberdade, imprevidência despreocupação, impetuosidade, jovialidade na vida, para gozar a vida. (Ibid. p.29)

\footnotetext{
"Existe algo na moral de Platão que não pertence realmente a Platão, mas que se acha apenas em sua filosofia; quase se poderia dizer, apesar de Platão: trata-se do socratismo, para o qual ele realmente era nobre demais." (NIETZSGHE, F. Sigo. In.: Além do Bem e do Mal. Trad.: Paulo César de Souza. - São Paulo: Cia das Letras, 2005): Platão seria, talvez, apenas mais um forte que não foi devidamente protegido dos doentes, no caso, protegido de Sócrates, porque "Os doentes são o maior perigo para os sãos; não é dos fortes que vem o infortúnio dos fortes, e sim dos fracos." (NIETZSCHE, F. "Terceira Dissertação", \$I4. In.: Genealogia da Moral. Trad.: Paulo César de Souza. - São Paulo: Cia das Letras, I998). No entanto, como nos referiremos à filosofia de Platão, bem como à de Sócrates, ao longo do trabalho, tomaremos ambas as filosofias sob a mesma crítica nietzschiana.

3 Será demonstrado ordenadamente: primeiro, a concepção nietzschiana de um conhecimento mais elevado; segundo, a concepção socrático-platônica sobre a verdade que culmina em seu método de conhecimento; terceiro, "como?" e "por quê?" as duas teorias não compactuam; e, quarto, que este tipo de conhecimento existe apenas enquanto criação - e que pertence aos "espíritos livres", como Nietzsche diz em Além do bem e do mal.
} 
O filósofo afirma que, mesmo depois de tantos séculos de conhecimentos, ainda repousamos na ignorância - que surgem no pensamento apenas desejos caprichosos e conclusões falsas; e que, porém, fazemos tudo isso para gozar a liberdade, a despreocupação, para gozar a própria vida. Ora, se, co mo no parágrafo anterior, não há determinados casos em que o homem vive em uma falsificação, mas, sim, em todo o seu viver, a própria vida é a base dessa falsificação. Porém, é justamente por causa disso que o homem goza a sua vida. O que Nietzsche está dizendo é que não há um sentido para a vida; mas não é estranho o prazer pela vida surgir bem na mentira, na falsidade, por causa da falta de sentido? O que Nietzsche nos quer dizer com isso?

O que é esta falsificação à qual Nietzsche se refere? Como ele disse, é o próprio viver: mas, por quê? No livro Sobre Verdade e Mentira no Sentido Extra-Moral, Nietzsche diz que não há nada que torna o homem mais especial do que qualquer outra coisa: não há intenções que o criaram como um ser sublime, não há nenhuma vontade especial que o admira, não há um fim, muito menos um começo, em que o homem seja o protagonista de uma trama universal e divina cuja inteligência o ponha em primeiro plano perante toda a natureza, de modo que:

Houve eternidades, em que ele não estava; quando de novo ele tiver passado, nada terá acontecido. Pois não há para aquele intelecto nenhuma missão mais vasta, que conduzisse além da vida humana. Ao contrário, ele é humano, e somente seu possuidor e genitor o toma tão pateticamente, como se os gonzos do mundo girassem nele. (NIETZSCHE, I974, p. 53)

A vida repousa, então, sobre uma total ausência de sentido, ou seja, sobre o mais sinistro de todos os hóspedes (NIETZSCHE, I974): o niilismo; disso resulta que também não há nenhuma verdade além da vida humana para nos guiarmos, para alcançarmos a não ser os nossos próprios valores, as nossas próprias morais tomadas como tais e, por isso, "a falsidade de um juízo ainda não é para nós nenhuma objeção contra esse juízo [...]" (ibid, p. 278): porque, justamente por não ter valor algum, o mundo pode ser "preenchido" por quaisquer valorações ${ }^{5}$;

4 Ou seja, as ações humanas são guiadas por si mesmas, e não por nenhuma Verdade cuja "essência" nos mostra a "coisa em si"; de modo que o "mundo humano" é pura moral: são nossas ações, "vontades" e forças que estão constantemente presentes no mundo (Cf. $A B M, \$ 22)$; crer em tais verdades é apenas uma crença metafísica (Cf. GC, \$344), um preconceito moral como diz Nietzsche em Além do Bem e do Mal.

5 Ou seja, por interpretações e concepções morais: o que é bom e o que é ruim/mau (termos distintos segundo a explicação de Nietzsche no seu livro Genealogia da Moral), o que é certo e errado, o que é verdadeiro e falso, etc.. 
porque, de certa forma, todo juízo é falso, faz parte dessa falsificação que Nietzsche fala. Seguindo essa ideia, o nosso conhecimento sobre o mundo é apenas uma interpretação, ou melhor, uma perspectiva criada pelo homem que, levada ao extremo, não pode ser classificada como errada ou certa, pelo simples fato de não haver nada, além do próprio homem, que a julga. Não há leis na natureza, por exemplo, não há verdades que possam sustentar a base do "certo" e do "errado" a ponto de desconsiderar ou considerar um juízo, de desprezar ou prezar um argumento $^{6}$.

O conhecimento para Nietzsche seria, então, uma parte da falsificação que o próprio viver cria. Ora, aqui chocamos por duas frentes (uma pela "falsificação" e a outra pela criação) com a concepção platônica sobre o conhecimento que se sustenta sobre as suas verdades metafísicas.

Platão distingue o conhecimento da opinião em algumas de suas obras. Para ele, a opinião é um parecer emitido por alguém que não contemplou devidamente a essência do objeto a que se refere, enquanto que o conhecimento é o contrário: ele é a contemplação fiel de uma essência e, por isso, de uma verdade (que futuramente chamaremos de verdade metafísica). "Então teríamos razão em afirmar que o pensamento dessa pessoa, que é alguém que conhece, é conhecimento, mas o do outro, que é alguém que emite um parecer seu, é opinião." (PLATÃO, 2006, p. 216). Na verdade, um dos objetivos dos diálogos platônicos, assim como nos parece ter sido também de Sócrates, foi desfazer os equívocos daqueles que pensavam que sabiam, mas não sabiam ${ }^{7}$.

Em boa parte, os sofistas foram os grandes alvos da dialética socrática; isso porque eles seriam a representação máxima de opinião que se confrontaria com o verdadeiro saber do filósofo. Além de várias outras definições que Platão dá em Sofista, o sofista não se importava com a verdade: os argumentos convinham

6 Para Nietzsche, as ideias, as formas de viver, de agir, de interpretar repousam em um terreno movediço cuja certeza ou incerteza, erro ou acerto, verdade ou inverdade fazem parte do confronto entre perspectivas e não da comparação com instâncias superiores, ou seja, Verdades e entes metafísicos. Disso surge a verdade de cada pessoa e, com isso, a valoração de cada perspectiva. Nota-se algo: o fato de tais perspectivas surgirem em confronto com as verdades metafísicas, como será visto, não significa que não haja verdades; mas que estas "verdades" não são dogmáticas, universais e eternas: são, isto sim, cada qual uma interpretação, uma espécie de fé de algo que se acredita, mas algo que se acredita vindo de si mesmo ou de outro, enfim, da própria vida. Isto será mais bem explicado ao longo do texto.

7 "Fui ter com um dos que passam por sábios, certo de que poderia assim controlar o oráculo e dizer-lhe claramente: 'eis aqui um mais sábio que eu, e tu disseste que eu o era'. Examinava a fundo o meu homem... Eis a impressão que me ficou do exame e da conversa que tive com ele: passava por sábio para muita gente e sobretudo para si mesmo, mas não o era... Retirei-me dizendo a mim mesmo: 'afinal de contas, sou mais sábio que ele'. Com efeito, é possível que nenhum de nós nada saiba de bom; somente, ele crê que sabe, se bem que não sabia; enquanto eu, se nada sei, também não creio saber. Parece-me, pois, que sou um pouco mais sábio que ele, ao menos nisto que não creio saber o que não sei.”. (SÓGRATES, Apologia. Col. Os pensadores. Ed. Abril Cultural -SP, I972.) 
conforme o seu contexto; daí ele tinha inúmeras explicações para as mesmas perguntas: pois, na maioria das vezes, se importava apenas com a persuasão de seu adversário. "Assim, deste ponto de vista, todas elas valem igualmente para ele." (PLATÃO, I972, p. I5I). No entanto, é a "arte de separar" e a "arte de purificar", como diz o Estrangeiro, que permite à alma um conhecimento verdadeiro:

Ela não alcançará, do que se lhe possa ingerir de ciência, benefício algum, até que se tenha submetido à refutação e que por esta refutação, causando-lhe vergonha de si mesma, se tenha desembaraçado das opiniões que cerram as vias do ensino e que se tenha levado ao estado de manifesta pureza e a acreditar saber justamente o que ela sabe, mas nada além.

(Ibid. p. I55)

Desta forma, a refutação criaria várias contradições nos que pensavam saber mas não sabiam, de modo que, separando e purificando o saber, mostraria o errado e o certo, ou melhor, o conhecimento e a opinião ${ }^{8}$. Mas, apenas a refutação não leva ao conhecimento do filósofo, já que, como é dito pelo Estrangeiro em Sofista, ela é a mais pura forma da sofística (PLATÃO, I972). É necessária uma espécie de olhar penetrante:

Aquele que assim é capaz discerne, em olhar penetrante, uma forma única desdobrada em todos os sentidos, através de uma pluralidade de formas, das quais cada uma permanece distinta; e mais, uma pluralidade de formas diferentes uma das outras envolvidas exteriormente por uma forma única repartida através de pluralidade de todos e ligada à unidade; finalmente, numerosas formas inteiramente isoladas e separadas; e assim sabe discernir, gêneros por gêneros, as associações que para cada um deles são possíveis ou impossíveis. (PLATÃO, I972, p. I84)

O conhecimento contempla o próprio ser em sua mais pura forma. Platão não cita diretamente o que os comentadores chamam de "Teoria das Formas" (ou "Mundo das Idéias" como o Mito da Caverna enquanto analogia nos leva a

8 Para Platão, assim como para Nietzsche - com suas devidas proporções e diferenças -, também há uma hierarquia: primeiro, o conhecimento - se refere ao ser; segundo, a opinião - que está entre o ser e o não-ser; terceiro, a ignorância - que se refere ao não-ser. "'-Então, se o conhecimento se refere ao ser e, necessariamente, a ignorância se refere ao não-ser, também se deve procurar, entre a ignorância e a ciência, um meio-termo cujo objeto seja esse meio-termo, se é que existe tal coisa?' [...] '- Ah! A opinião seria um meio-termo entre os dois?" '- Certamente." (PLATÃO. "Livro V, 477a -478d”. In.: A República.) 
pensar). No entanto, a sua filosofia considera que as informações que os nossos sentidos nos dão pertencem à corruptibilidade e imutabilidade, de modo que não podemos atingir um conhecimento pleno e seguro sobre as coisas, pois eles podem mudar a qualquer momento, influenciados por uma série de causas como o simples engano da visão; em contraposição a estes "conhecimentos", ou melhor, a estas opiniões, existiria a verdadeira forma de conhecimento: ou seja, aquela que se referiria ao próprio ser e à sua essência.

Sendo assim, o conhecimento, para Platão, se refere somente à verdade (caso contrário, é opinião). Busca-se, então, nesse ser, as características que o constituem, ou seja, a sua essência; tal essência define uma coisa de modo que ela não se confunda com nenhuma outra: assume que ela deve ter características imutáveis e únicas, porque, se não, ela deixaria de ser o que é. Analisando através da lógica: na essência de algo, está presente sempre o que o define como o que é, ou seja, como único e existente - por exemplo, e, superficialmente, diz-se que uma das características da essência de uma cadeira é possibilitar que alguém se sente nela, de modo que, se essa característica mudar para que alguém se deite nela, a cadeira se torna uma cama. Assim, o conhecimento para Platão busca características que estão sempre presentes no objeto estudado, ou seja, ele conhece a essência de cada objeto a fim de buscar dados verdadeiros que o compõem. Dessa forma, como consequência, o engano, o incerto, o erro, o mutável aparecem em contraposição a esse conhecimento que permite estudar, entender, ou seja, descobrir o que existe na realidade sem se enganar - percebe-se então dois planos: o da realidade e o da ilusão. O interessante é que o plano da realidade não é ao que estamos submetidos, o que vivemos, mas uma "dimensão" outra mais sublime cuja verdade é inalcançável para nós devido aos constantes vícios que os nossos corpos possuem, impossibilitando o pleno conhecimento $^{9}$. Dessa forma, a verdade estaria em algo além do próprio homem - em qualquer lugar (físico ou não) que não aqui no mundo e em nós -, de modo que o conhecimento não poderia fazer parte de um lugar efêmero e suscetível às constantes transformações. O conhecimento independeria, então, do próprio homem, a quem restaria apenas descobrir essências; a verdade pairaria em um plano intocável por quaisquer mãos humanas cujo resultado daria ao homem apenas a insígnia de um imperfeito descobridor ontológico, pois sua máxima descoberta residiria abissalmente na própria realidade e verdade. Nota-se, então, que este conhecimento e esta verdade são metafísicos, apesar de Platão poucas vezes, para não dizer nunca, se referir desta forma.

9 No diálogo Fédon, esta concepção fica evidente: Sócrates não está triste pela sua condenação à morte; ao contrário, está feliz porque vai se livrar justamente das causas que o impossibilitam de ter um verdadeiro conhecimento e, por isso, contemplar o Bem. 
O confronto entre Nietzsche e Platão surge nitidamente: o primeiro se refere ao conhecimento como uma falsificação e interpretação da vida, enquanto o segundo se refere ao conhecimento como uma verdade e descoberta do ser.

O método de busca pela verdade e pelo conhecimento considerado o mais sublime por Platão é, para Nietzsche, uma anulação de vontade:

"Vontade", naturalmente, só pode fazer efeito sobre "vontade" - e não sobre "matéria" (não sobre "nervos", por exemplo): é o que basta para termos de arriscar a hipótese, se por toda parte onde são reconhecidos "efeitos" não é vontade que faz efeito sobre vontade - e se todo acontecer mecânico, na medida em que uma força é ativa nele, não é justamente força de vontade, efeito de vontade. (NIETZSCHE, I974, p. 282)

Para Nietzsche, o mundo se constitui por forças - no homem, sobretudo, é a vontade que atua de alguma forma sobre o seu agir. Mas a vontade para Nietzsche não é uma escolha de um "eu", de um "sujeito", que se separa de seu verbo, ou melhor, de sua ação: considerar que um "eu" comanda a ação é também cair em uma dualidade metafísica que entende o corpo como algo separado de sua "alma", como se o corpo fosse apenas um transporte temporário possuído e ordenado por alguma espécie de espírito, quando, na verdade, ele é, para Nietzsche, o que gera o pensamento e, por isso, parte inseparável dele. Quando este "eu" - o mesmo que a gramática utiliza - é considerado como comandante de sua ação, também se tem a noção de que ele possui liberdade, isto é, de que basta o seu querer para que qualquer ação seja cumprida. “O que é chamado 'livre-arbítrio' é, essencialmente, o afeto de superioridade em relação àquele que tem de obedecer: 'eu sou livre, 'ele' tem de obedecer' [...]. Um homem que quer - comanda algo dentro de si que obedece, ou que ele acredita que obedece." (NIETZSCHE, 2005, p. 2I). Assim, bastaria que alguém dissesse "eu quero" para que sua ação estivesse garantida, no entanto, com isso, também se desconsideraria todo o processo corporal, ou melhor, fisiológico que leva à determinada ação. Para Nietzsche, então, querer e vontade são coisas diferentes, mesmo que em alguns casos elas se unam: não basta que o querer exista, é necessário principalmente que a vontade atue nele.

Mas agora observem o que é mais estranho na vontade - nessa coisa tão múltipla, para a qual o povo tem uma só palavra: na medida em que, no caso presente, somos ao mesmo tempo a parte que comanda e a que obedece, e como parte que obedece conhecemos as sensações de coação, sujeição, pressão, resistência, movimento, que normalmente têm início logo após o ato da vontade; na medida em que, por outro lado, temos o hábito de ignorar e nos enganar 
quanto a essa dualidade, através do sintético conceito do "eu", toda uma cadeia de conclusões erradas e, em consequência, de falsas valorações mesma, veio a se agregar ao querer - de tal modo que o querente acredita, de boa-fé, que o querer basta para agir. (Ibid. p. 23)

Além da dualidade metafísica entre corpo e alma que o conceito de "eu" leva a acreditar, a sensação de comando que ele gera disfarça a sua obrigatória sujeição: para que a sua ordem "eu quero" seja executada, ele mesmo deve também dizer "eu obedeço". No entanto, esse processo, mesmo que não revelado completamente pelo sintético conceito do "eu", como Nietzsche diz, esconde outro fator importante: para Nietzsche tudo isso é consequente de inúmeras relações de impulsos básicos e primitivos, como as funções orgânicas de nutrição, alimentação, metabolismo, crescimento, "[...] pois pensar é apenas a relação desses impulsos entre si [...]" (NIETZSCHE, 2005, p. 39). O pensamento e a ação - os mesmos que estes "eu quero" e "eu obedeço" - são gerados pela vontade que é várias relações de impulsos básicos. A vida é então essa vontade.

Supondo, enfim, que desse certo explicar toda a nossa vida de impulsos como a conformação e ramificação de uma forma fundamental da vontade ou seja, da vontade de potência, como é minha proposição -; suposto que se pudessem reduzir todas as funções orgânicas a essa vontade de potência e nela também se encontrasse a solução do problema da geração e nutrição - isto é um problema -, com isso se teria adquirido o direito de determinar toda força eficiente univocamente como: vontade de potência. $\mathrm{O}$ mundo visto de dentro, o mundo determinado e designado por seu 'caráter inteligível' - seria justamente 'vontade de potência', e nada além disso. (NIETZSGHE, I974, p. 282).

Tudo, segundo Nietzsche, é esta vontade que almeja sempre mais: o caráter inteligível do mundo faz parte dela: deseja efetivar-se. As vontades se confrontariam então de acordo com as suas forças, de modo que as mais fortes subjugam as mais fracas. Surge uma relação entre quem domina e quem é dominado quando uma vontade se sobrepõe a outra "vontade". Porém, esse sobrepor é condição necessária da própria vida; de acordo com Nietzsche, é justamente isso que proporciona um aumento de potência e não a mera conservação do homem. “A ‘exploração' não é própriadeumasociedadecorrompida, ou imperfeita eprimitiva: faz parte da essência do que vive, como função orgânica básica, é uma conseqüência da própria vontade de poder, que precisamente é vontade de vida." (NIETZSGHE, 2005, p. I54); assim, essa vontade dominante, em contraposição à dominada, se revela como 
criadora de valores - mas valores que existem como glorificação de si. "O homem de espécie nobre se sente como determinante de valor, [...] sabe-se o único que empresta honras às coisas, é criador de valores. Tudo o que ele conhece em si, ele honra: uma tal moral é glorificação de si." (Ibid. p. I55).

O problema é quando uma verdade - motivada por uma vontade que quer dominar - se impõe perante outras concepções, almejando anulá-las.

Atentemos para o seguinte: para se buscar a verdade - encontrar a essência da coisa, as características da "coisa em si", em contraposição às aparências, enganos, erros, como queria Platão -, deve-se anular totalmente as criações de alguém; caso contrário não há conhecimento, mas opinião, como foi visto acima. Ora, se a verdade é a revelação da realidade, ou melhor, a descoberta de uma propriedade, de uma lei essencial a um objeto, então nada se tem para criar ali, nada é do próprio homem. O conhecimento assim não é uma criação humana, mas uma descoberta de essências - de regras que aprisionam o pensamento. Dessa forma, o conhecimento se mostra totalmente desinteressado, ou seja, nele não contém nenhuma intenção, nenhuma vontade, nenhum fim; o homem mesmo é anulado - a sua vontade, desejo, criação não significam nada diante de um objeto que tem a sua verdade. A concepção platônica de conhecimento é uma descoberta cujo resultado não pode ter influência do homem; quanto menor for o seu grau de subjetividade, mais alto é o nível do conhecimento. Com isso se revela também que não há nenhum interesse do homem ao conhecer, a não ser o próprio conhecimento; ele apenas descobre uma verdade do ser estudado. Mas, se, de acordo com Nietzsche, não há nada no homem que não seja uma vontade e não há nada além dos seus próprios sentidos, e se este conhecimento não é uma criação, mas uma adoção, então, qual é o perigo de se acreditar em verdades como as de Platão?

"Conhecimento pelo conhecimento' - eis a última armadilha colocada pela moral: é assim que mais uma vez enredamos inteiramente nela" (NIETZSCHE, 2005 , p. 62). Por que o "conhecer por conhecer" nos enreda mais uma vez em uma armadilha da moral? Porque ao fazer isso, o que pertence ao homem - o seu desejo, a sua vontade, o seu instinto, a sua criação, o seu pensamento - é posto de lado, é inutilizado. Dessa forma, o homem se anula perante uma "verdade" encontrada apenas para o conhecimento e não para ele próprio. "O homem objetivo é de fato um espelho: habituado a submeter-se ao que quer ser conhecido, sem outro prazer que o dado pelo conhecer, 'espelhar' [...]" - nada é dele, tudo é uma descoberta e não uma criação - "O que lhe resta ainda de 'pessoa' lhe parece causal, não raro arbitrário, com frequência perturbador: de tal modo se tornou reflexo e passagem de formas e acontecimentos alheios." (Ibid. p. 
97). A busca pela verdade, segundo o método platônico, esse "conhecimento", se transfigura em moral, em algo disciplinador, condutor, aprisionador. A filosofia, a pedagogia, a psicologia etc., dessa forma, se anulam enquanto um meio para a criação de conhecimento, sendo que o que se aprende se torna reprodução, isto é, o homem apenas descobre o conhecimento de que outros lhe falaram, de modo que os seus próprios pensamentos se anulam por não condizerem com o estatuto de Verdade. Mas, se esse "homem objetivo" é mero reflexo, é neutro, é vago, então, nele, usando uma metáfora, há espaço para que outros o utilizem aqueles que sabem fazer isso, que sabem que essa objetividade é apenas anulação de interesse, de querer, de vontade: os moralistas; "ele é um instrumento, algo como um escravo, certamente a mais sublime espécie de escravo, mas nada em si [...]" (NIETZSGHE, 2005, p. 99). Ora, tudo aquilo sobre vontade e querer que falamos acima convém aqui: ao acreditar que há verdades na "coisa em si", na essência do ser, o homem apenas revelaria algo que existe independente dele; mas e quem revelou tal característica do ser? O que garante, além desse revelador, que ela exista objetivamente independente dele? Segundo Nietzsche, tudo isso é apenas mais uma transfiguração da vontade de potência que quer dominar: aquele que acredita em tais verdades apenas está adotando o que outro "revelou" - ou melhor, o que outro criou - e deixando as suas próprias concepções de lado. Dizer uma opinião, como diria Platão, é expor um parecer seu; mas deixá-la de lado a fim de um "conhecimento verdadeiro", como diria Nietzsche, é expor um parecer de outro. Em suma, ambas as situações, de acordo com Nietzsche, revelariam uma opinião. O conhecimento platônico também é uma criação, mas uma criação que não permite que ninguém crie mais nada: que permite apenas que a aceitem. As questões são: de quem é esta opinião? Ela é criada ou adotada? Ela é decorrente de uma vontade que a criou ou que a "descobriu"?

O método platônico de busca pela verdade acaba por objetivar o conhecimento e, portanto, por limitar o campo de criação, talvez até por eliminálo. "O homem objetivo é um instrumento, um precioso, facilmente vulnerável e embaçável instrumento de medição e jogo de espelhos [...]; mas ele não é uma meta, não é uma conclusão e elevação [...] que aspire a dominar" (Ibid. p. 99). Ao contrário, ele é dominado pela "verdade" da "coisa em si". Nota-se então o seguinte: quando o homem realiza um conhecimento objetivo ${ }^{\mathrm{IO}}$, a fim de encontrar a verdade da coisa em si, ele anula o seu pensamento enquanto

Io Para Nietzsche, o simples fato de "separar" sujeito de objeto, ou melhor, o homem do mundo, já é algo absurdo, de modo que essa discussão não tem nexo; porém, para não aumentarmos o tema proposto, ao menos não neste artigo, analiso como esse "conhecimento objetivo" se enraíza no campo da moral e atua sobre o homem através da coerção, obrigação, anulação, tornando inútil o seu pensamento. 
criação sua, e também admite facilmente e sem contestação o que lhe dizem ser uma "verdade".

Essa forma de conhecimento leva o homem a um aprisionamento físicoteórico. Primeiro - porque ele é apenas um descobridor de verdades, de leis, de regras, que estão escondidas sob a aparência que a nossa percepção capta; por conseguinte, ele também não cria nada, não determina, pelo contrário, ele é determinado pelo próprio conhecimento e, por isso, se torna também um instrumento dele: a sua vontade, o seu querer e até o seu pensamento estão condicionados às regras que cada verdade contém - e todo o mérito também se volta apenas para uma descoberta, para um simples instrumento chamado homem. Consequentemente, o que já foi descoberto não pode ser repensado, cogitado, refutado, porque ele se emaranha no conceito de verdade, de essência, de certo, e, então, se consuma como conhecimento. Mas um conhecimento dogmático, tirano, por assim dizer, que obriga o próprio homem a aceitá-lo ${ }^{I I}$. Àquilo que foi descoberto, só resta ser transmitido, só resta o entendimento sem debate. O conhecimento platônico impede a criação, a reformulação, a contestação, a refutação de ideias - de modo que os alunos, professores, pesquisadores, por exemplo, são aprisionados em verdades e, assim, se enquadram na figura de meros transmissores e compartilhadores, mas nunca na de criadores de conhecimento.

\section{Conclusão}

Ao contrário das verdades platônicas, Nietzsche cria uma outra perspectiva sobre o conhecimento.

A palavra "busca", de acordo com a concepção nietzschiana, necessariamente precisa de aspas, pois ela não está empregada da mesma forma que a busca - pela verdade - de Platão: sua intenção não é a de encontrar, de descobrir, de ter algo que não se tem, mas - como uma espécie de redundância no título - a de criar. Isto porque, diferentemente de Platão, o conhecimento não pode ser buscado, pois ele é tido conforme se vive; pois, de uma maneira bem geral, ele é o próprio ato de viver - querer buscá-lo é se iludir e, para isso, basta viver. "Portanto não creio que um ‘impulso ao conhecimento' seja o pai da filosofia, mas sim que um

II Note-se que uma verdade é descoberta por alguém, segundo o método aqui analisado, e, por ser verdade, ela deve ser aceita; quem deve aceitá-la são os homens, sobretudo aqueles que as estudam: logo, essa verdade serve também como condicionamento, disciplinamento. 
outro impulso, nesse ponto e em outros tenha se utilizado do conhecimento (e do desconhecimento!) como um simples instrumento. [...] Pois todo impulso ambiciona a dominar: e portanto procura filosofar.-"(NIETZSCHE, 2005, p. I2). Expliquemos melhor: segundo Nietzsche, o conhecimento é um impulso que almeja a dominar, ou melhor, cuja vontade não suporta obedecer a vontades extrínsecas: ele faz parte de quem é forçado por seus impulsos a querer comandar em vez de obedecer. Mas para isso é preciso que o próprio conhecimento não seja adotado, descoberto, como as verdades metafísicas de Platão; ao contrário, o conhecimento de quem a vontade quer dominar cria a si mesmo: cria os seus próprios valores. Aceitar, criticar, contradizer, colecionar, descobrir, moralizar, sim, também fazem parte do processo de conhecer. "Mas tudo isso são apenas precondições de sua tarefa: ela mesma requer algo mais - ela exige que ele crie valores." (NIETZSCHE, 2005, p. I05). Nota-se, então, que existem dois conhecedores: um do tipo platônico - que apenas descobre verdades e se cala perante elas - (como é a nossa problemática) e um do tipo nietzschiano que esnoba tais verdades ao criar as suas (como é a nossa hipótese). A este último, Nietzsche nomeia, na obra Além do Bem e do Mal, espírito livre e filósofos do futuro.

Dessa forma, a "busca" do espírito livre pelo conhecimento acontece de forma tão natural que mal se percebe. Na verdade, os seus impulsos o levam a isso. "E quem procura ser independente sem ter obrigação disso, ainda que com todo o direito, demonstra que provavelmente é não apenas forte, mas temerário além de qualquer medida." (Ibid., p. 34). Ele simplesmente vive conforme a sua vontade é guiada por seus impulsos. O espírito livre não teme estar errado, não almeja estar certo: puramente vive o que é. Este simples fato o faz diferente de qualquer outro: o torna forte, ou melhor, mostra que ele é forte. Como Nietzsche diz, ele se põe em jogo, se testa, quer errar, não se importa com possíveis inverdades de seus juízos porque se lembra da falsificação na qual a vida está e dificilmente se cega por uma verdade, não quer que a sua verdade - talvez, universal e eterna apenas para ele - se torne também verdade para os outros. "Serão novos amigos da 'verdade' esses filósofos vindouros? Muito provavelmente: pois até agora todos os filósofos amaram as suas verdades. Mas com certeza não serão dogmáticos." (Ibid., p. 44). Porque sabe que aquela falsificação contida na vida, que foi citada nos primeiros parágrafos deste texto, resigna julgamentos moralizadores e dogmáticos. A ardilosa e enorme diferença entre a concepção de conhecimento de um espírito livre de Nietzsche e a concepção de conhecimento de Platão está no fato de que um é criação para si de modo natural e o outro é criação para os 
outros de modo dogmático.

No âmbito do espírito livre, um conhecimento criador pode surgir: o seu conhecimento, a sua "[...] melhor ciência procura nos prender do melhor modo a esse mundo simplificado, completamente artificial, fabricado, falsificado, e de como, involuntariamente ou não, ela ama o erro, porque, viva, ama a vida!" (NIETZSCHE, 2005, p. 29). O conhecimento deste espírito livre é dominar, o dominar é criar valores, e esta criação é viver. A fórmula é mais ou menos esta : conhecer $=$ dominar $=$ criar valores $=$ viver de modo forte ao estilo de um espírito livre. Assim, esta forma de conhecimento só pode existir no espírito livre enquanto sua criação ${ }^{12}$ : porque a sua forma de vida é sua vontade de poder ${ }^{13}$; a sua vontade de poder é sua vontade de verdade ${ }^{\mathrm{I4}}$; sua vontade de verdade é dominar, seu dominar é criar, e seu criar é conhecer. Portanto, à luz da crítica de Nietzsche à verdade metafísica de Platão, surge a perspectiva, no espírito livre, de uma "busca" de conhecimento enquanto criação: pois "seu 'conhecer' é criar [...]" (Ibid. p. IO6).

\section{Referências Bibliográficas:}

FOGEL, GILVAN. Conhecer é criar: um ensaio a partir de F. Nietzsche. $-2^{\mathrm{a}}$. ed. - São Paulo: Discurso Editorial; Ijuí, RS: Ed. Unijuí, 2005. - (Sendas \& Veredas / coordenadora Scarlett Marton).

NIETZSCHE, F. W. Além do Bem e do Mal. Tradução, notas e posfácio de Paulo César de Souza. - São Paulo: Companhia das Letras, 2005.

Crepúsculo dos Ídolos. Tradução, notas e posfácio de Paulo César de Souza. - São Paulo: Companhia das Letras, 2006.

Genealogia da Moral. Tradução, notas e posfácio de Paulo César de Souza. - São Paulo: Companhia das Letras, I998.

O Anticristo. Tradução, notas e posfácio de Paulo César de Souza.

- São Paulo: Companhia das Letras, 2007.

A Gaia Ciência. Tradução, notas e posfácio de Paulo César de Souza. - São Paulo: Companhia das Letras, 200I

I2 Isso não quer dizer que não haja para Nietzsche outras formas de conhecer sob outras formas de viver: o conhecimento objetivo, por exemplo - entre outros.

I3 “[...] vida é precisamente vontade de poder." Nietzsche, F. \$259. In.: Além do Bem e do Mal. Ed. Gia das Letras, 2005 .

I4 "[...] sua vontade de verdade é - vontade de poder." Nietzsche, F. \$2II. In.: Além do Bem e do Mal. Ed. Cia das Letras, 2005. 
Aurora. Tradução, notas e posfácio de Paulo César de Souza. São Paulo: Companhia das Letras, 200I.

- Humano, demasiado humano. Tradução, notas e posfácio de Paulo César de Souza. - São Paulo: Companhia das Letras, 2005.

NIETZSGHE, FRIEDRICH / Obras Incompletas. Tradução de Rubens Rodrigues Torres Filhos. - I. ed. - São Paulo: Abril Cultural, I974. Coleção Os Pensadores.

NIETZSGHE : Filosofia e Educação / organizadora Vânia Dutra de Azevedo. - Ijuí: Ed. Unijuí, 2008 (Coleção Nietzsche em perspectiva).

NOVA, MARGO ANTONIO GASA. Interpretação enquanto princípio de constituição do mundo. In.: Cadernos Nietzsche IO, p. 27-47, $200 \mathrm{I}$.

PLATÃO, "A República”. São Paulo: Martins Fontes, 2006. Tradução de Anna Lia Amaral de Almeida Prado.

PLATÃO. Crátilo; tradução de Carlos Alberto Nunes. - 3. ed. ver. . Belém: EDUFPA, 200 I.

PLATÃO. Sofista. Coleção Os Pensadores, ed. Abril Cultura, I972.

PLATÃO. Teeteto; tradução de Carlos Alberto Nunes. - 3. ed. ver. Belém: EDUFPA, $200 \mathrm{I}$.

ZATERKA, LUGIANA. Nietzsche: a "verdade" como ficção. In.: Cadernos Nietzsche I, p. 83-92, I996.

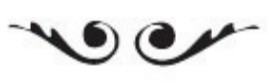

Marco Sabatini é graduando em Filosofia pela UNIFESP.

E-mail: marco_rsabatini@hotmail.com 